\title{
Improving neural network for flood forecasting using radar data on the Upper Ping River
}

\author{
$\underline{\text { T. Chaipimonplin }}^{\text {a,b }}$, L. See ${ }^{\text {b,c }}$ and P. Kneale ${ }^{\text {d }}$ \\ ${ }^{a}$ Department of Geography, Faculty of Social Sciences, Chiang Mai University, 50200, Thailand \\ Email: tawee.c@,cmu.ac.th \\ ${ }^{b}$ School of Geography, University of Leeds, Woodhouse Lane, Leeds, LS2 9JT, UK \\ ${ }^{c}$ International Institute of Applied Systems Analysis, Schlossplatz 1, A-2361 Laxenburg, Austria \\ ${ }^{d}$ Teaching and Learning Directorate, 3 Endsleigh Place, University of Plymouth, Drake Circus, Plymouth, \\ PL4 8AA, UK
}

\begin{abstract}
Artificial Neural Networks (ANNs) and other data-driven methods are appearing with increasing frequency in the literature for the prediction of water discharge or stage. Unfortunately, many of these data-driven models are used as the forecasting tools only short lead times where unsurprisingly they perform very well. There have not been much documented attempts at predicting floods at longer and more useful lead times for flood warning. In this paper ANNs flood forecasting model are developed for the Upper Ping River, Chiang Mai, Thailand. Raw radar reflectively data are used as the primary inputs and water stage are used as the additional inputs, also four input determination techniques (Correlation, Stepwise regression, combination between Correlation and Stepwise Regression and Genetic algorithms) are applied to select the most appropriated inputs. Normally, the ANNs model can predict up to 6 hours when only water stage used as the input data and the lead time can be increased up to 24 hours by using only radar data. In addition, combination of the input between water stage and radar data, gave the overall result better then using only water stage or radar data, also selecting different appropriated inputs could improve model's performance.
\end{abstract}

Keywords: neural network, flood forecasting, radar data, Chiang Mai 


\section{INTRODUCTION}

Flooding occurs in Thailand almost every year during the monsoon season. Chiang Mai is the biggest city in the northern part of Thailand and located in Ping catchment. This city experienced the biggest flood in 2005. To reduce the loss of life and the damage caused by flooding, early warning systems with timely and accurate forecasts are needed. The hourly history data at Chiang Mai is limited in both record length and number of gauging station across the catchment. Therefore to forecast floods in Ping catchment is a challenge. The current method of flood warning in Chiang Mai city is based on a correlation between water level at the upstream station (P67) and the downstream station (P1) with the maximum time for flood warning 6-7 hours (Hydrology and Water Management Centre for Upper Northern Region, 2007a, b). There are a number of conceptual and physical hydrological models which were used in this catchment but did not forecast in hourly (Taesombat and Sriwongsitanon, 2010).

Artificial Neural Networks (ANNs) is one type of data driven method. Numerous studies have demonstrated that ANNs or other data-driven methods can be used successfully for rainfall-runoff modelling and other hydrological applications as evidenced by recent reviews Abrahart et al. (2010) and Maier et al. (2010). The neural network models only require historical input data for development and not physical parameters as in other physically-based or conceptual hydrological models (ASCE, 2000). There are not many research using ANNs for flood forecasting in hour in Thai catchment. Most of the research focuses on daily or monthly.

To determine whether models with hourly long lead times can be developed, investigations with weather radar data have been undertaken. Weather radar data are normally used for calibrating rainfall using rain gauges (Chumchean, 2007) in order to predict rainfall (Cole and Moore, 2008). Other researchers have specifically applied this to flood forecasting (Wardah et al., 2008). However, only one paper predicts flood using raw radar reflectivity (dBZ value) as an input to ANNs (Chaipimonplin et al., 2010). There is only one hourly rain gauge near Chiang Mai so using the radar data with this one rain gauge would not have been very useful. Instead, the method used for this study takes advantage of the spatial and temporal coverage of the radar images. The objective of this study is to improve the leading time for flood warning by using both water level and raw $\mathrm{dBz}$ value of radar image

\section{STUDY AREA AND DATA}

The Ping catchment is located in the Northern part of Thailand (Figure 1). Moreover, this catchment is divided into two parts: the Upper and the Lower Ping. The Upper Ping is a large complex river basin covering two provinces $\left(17^{\circ} 14^{\prime} 30^{\prime \prime}-19^{\circ} 47^{\prime} 52^{\prime \prime} \mathrm{N}, 98^{\circ} 4^{\prime} 30^{\prime \prime}-99^{\circ} 22^{\prime} 30^{\prime \prime}\right.$ E); Chiang Mai and Lam Phun (Mapiam and Sriwongsitanon, 2009). It has an area of approximately $23,600 \mathrm{~km}^{2}$. The distance from the source of the river to Chiang Mai city is $190 \mathrm{~km}$ (Hydrology and Water Management Centre for Upper Northern Region, 2007a). This study focuses on forecasting water level at P1 station that is located in the centre of Chiang Mai city (Figure 2). Water level data are available for P1 and three upstream water level stations; P67, $\mathrm{P} 4 \mathrm{a}$ and P75. Monsoon rainfall in Thailand comes from northeast weather systems (November to February), which brings moisture from the South China Sea, and from the southwest monsoon (May to September), which brings rain

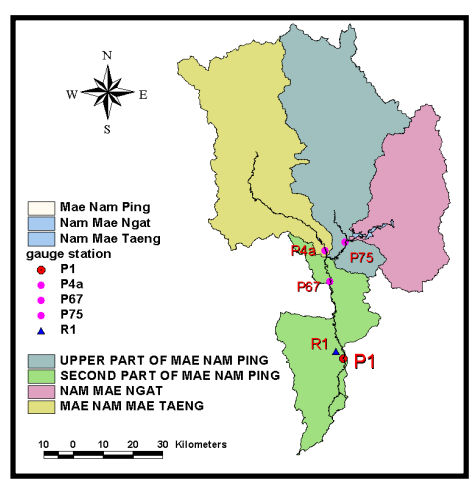

from the direction of the Indian Ocean (Boochabun et al., 2004). According to Northern Meteorological Center (2007), the wettest month is August,

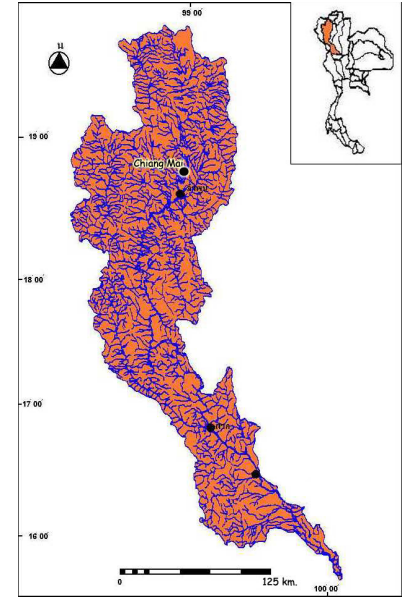

Figure 1. The Ping catchment. Source: Department of Water Resources (2007) which has an average rainfall of approximately $224.4 \mathrm{~mm}$; whereas, the driest month is January with $7.7 \mathrm{~mm}$. Moreover, the average annual rainfall is $1,180 \mathrm{~mm}$ and the range of average annual rainfall is 900 to 1,900 mm (Hydrology and Water Management Centre for Upper Northern Region, 2007b)

Figure 2. Locations of water level stations. 
In addition, flood occurs in Chiang Mai city when the water discharge is greater than $400 \mathrm{~m} 3 / \mathrm{s}$ and the water level exceeds $3.70 \mathrm{~m}$ (above a datum) (Hydrology and Water Management Center for Upper Northern Region, 2007b). Flood events more recently have been higher when compared with previous decades. In the past, the flood level at P1 had been $3.40 \mathrm{~m}$. After excavation of the Ping River channel and build the flood defense wall in 2004, the flooding level increased to $3.70 \mathrm{~m}$ (Department of Water Resources, 2007).

The radar is used to detect precipitation using the CAPPI (Constant Altitude Plan Position Indicator) techniques. The spatial resolution of the radar image is $1 \mathrm{~km}$ and temporal resolution is between 6 minutes and 1 hr with a ground coverage radius of $240 \mathrm{~km}$. The radar images from Chiang Mai station are used in this study and the rectangle is the study area (Figure 3). The colour bar indicates the intensity of precipitation as blue indicates the heavy rain. In the past studies, radar data have been used to estimate rainfall. For example, a suitable Z-R relationship for the northern part of the Thailand catchment was found to be $Z=300 \mathrm{R} 1.4$ (Rachaneewan, 2006). However, the radar data require calibration and there was only data from one rain gauge available. Instead, this study was decided to use the raw radar data to see whether this rich source of spatial data could improve the lead time of the ANNs forecast. Radar images are only available for 2003, 2005 and 2006. Figure 4 presents all eights storms that occurred during this period and the missing radar images are the first two storms in 2006. The S2 is the biggest storm so it was selected as the testing dataset which were developed for lead times of 12,18 and 24 hours ahead.

\section{METHODS}

\subsection{Artificial Neural Networks (ANNs)}

ANNs are a type of biologically inspired computational model, which has been loosely based on the functioning of the human brain. ANNs perform an input-output mapping using a set of simple

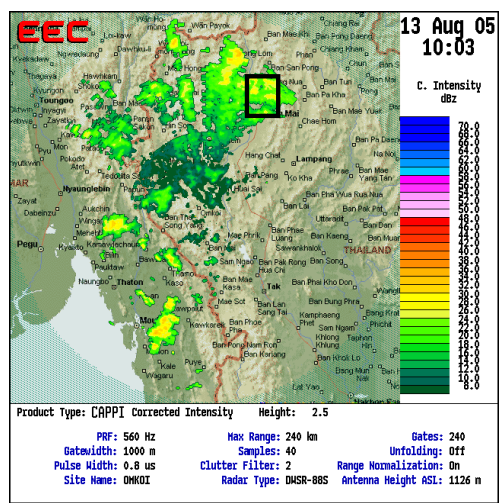

Figure 3. Example of radar images covering the study area.

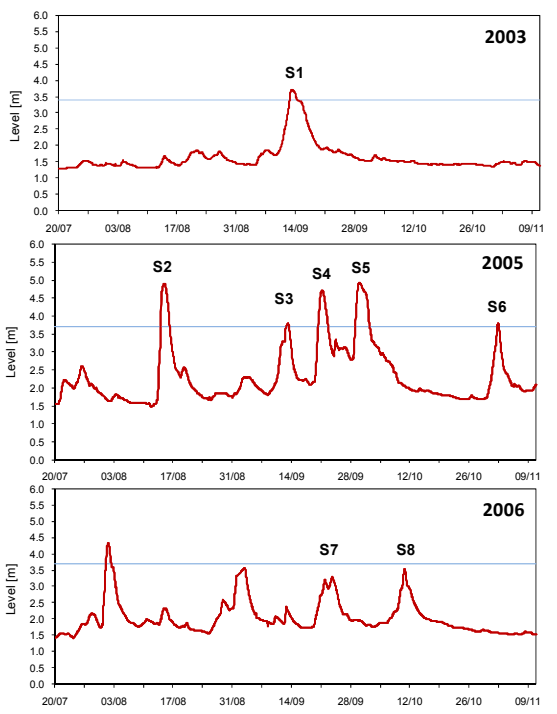

Figure 4. Storms in 2003, 2005 and 2006. processing nodes or neurons where the inputs are drivers to the process and the output in the case of this research is the river level in the future for a specific lead time. Each individual neuron integrates information from the model input or from other neurons and outputs this value using a transfer function. ANNs consist of a series of these neurons arranged in a set of weighted, interconnected layers. Data enter the network through the input units arranged in an input layer. These data are then feed forward through successive layers including the hidden layer in the middle to emerge from the output layer. ANNs development involves two main stages; training and testing. In the training or learning stage, the weights between the neurons are adjusted until the network is capable of prediction the desired output. Backpropagation is one of many different training algorithms that are available. In this paper ANNs are trained with Bayesian Regularisation (BR) which has been used in hydrological application (Anctil, 2007; Chaipimonplin, et al., 2008, 2010).

\subsection{Radar Images}

The image was sampled at 9 points covering the river with a distance of $10 \mathrm{~km}$ between points. The points were labeled as $Z 21,22$, etc. to reflect the row and column, the distance from the point $Z 42$ to $\mathrm{P} 1$ is $10 \mathrm{~km}$ (Figure 5). The $3 \times 3$ pixels directly surrounding each of the 9 points were also extracted in order to create the different method strategies.

\section{Different Methods of Sampling Strategies}

There are four methods of strategies as follows:

- Sum Step: sums all 9 pixel values at 6 hour intervals, e.g. t, t-6, .., t-24;

- Aver Step: same as Sum Step except the values are averaged instead of summed;

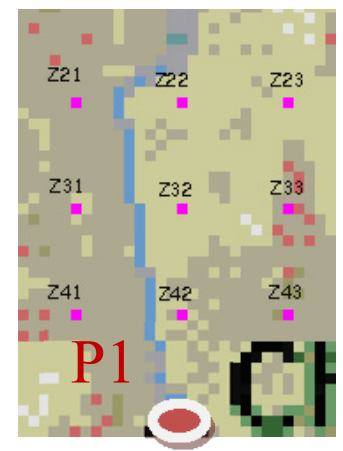

Figure 5. Nine sample points of radar image. 
- Sum Accum: same as Sum Step except that cumulative values are calculated, e.g. the sum of t to t-5, t- 6 to $t-11$, etc. up to t24 ;

- Aver Accum: same as Sum Accum except that the initial nine pixels are first averaged and then a cumulative value over a 6 hour interval is calculated.

It can be seen that increasing lead time improved the model performance also sum and average of accumulated $\mathrm{dBZ}$ value gave the same result (Figure 6). However, using time step gave the fluctuated hygrograph.

\section{Extending the Sample Area and Number of Sample Points}

Extra 11 sample points were added in the study area over the catchment (Figure 7) and used all 20 points as the input variables. Increasing the number of sample points across the catchment resulted in a slight improvement in the model performance (Figure 8).

\subsection{Input Determinations}

One of the major difficulties of the ANNs modelling also other datadriven modelling is deciding upon which input variables should be used. Even though, the knowledge of hydrological can be helpful in selecting the input variables, it is still unclear which variable to be selected, how much to lag the variables for travel time, whether moving averages should be included etc. As a result, the input determination techniques were used. Chaipimonplin (2010) investigated eight input determination techniques; Correlation between input and output is greater than 0.90 (C), Stepwise regression (S), combination technique between Correlation and Stepwise regression (CS), Partial Mutual Information (PMI), Pruning Algorithms (Pr), Genetic Algorithms (G), M5 model trees (M), and Data
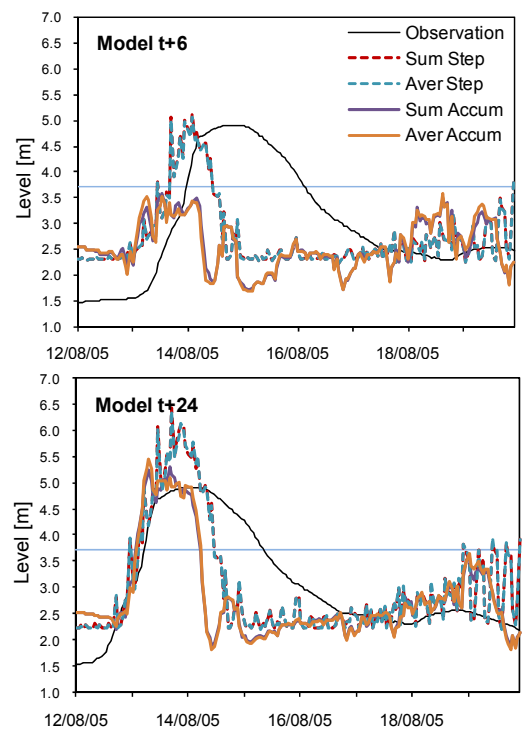

Figure 6. Hydrographs of 4 models using only radar image.

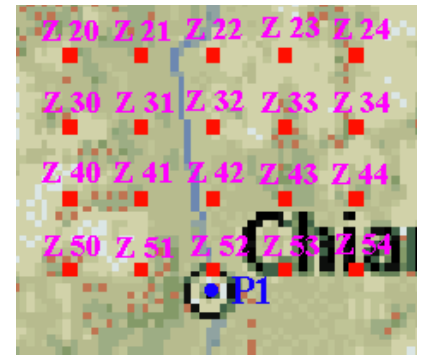

Mining (D). He concluded that the most suitable techniques for flood forecasting at Upper Ping River are C, S, CS and G. Therefore, these four input determination techniques were used in this study. The WEKA software was used to run the Genetic Algorithms (Witten and Frank, 2005) and SPSS statistical software was used to calculate the correlation and to perform Stepwise linear regression.

According to Chaipimonplin et al. (2010), the best lead time using only water level is 6 hours and 24 hour using only radar images (Figure 9). Moreover, it is clear that the prediction of the rising limb of the hydrograph and the peak are both exceptionally good at all of these extended lead times. However, the falling limb of the hydrograph $t+24$ that using only radar image fails down earlier than

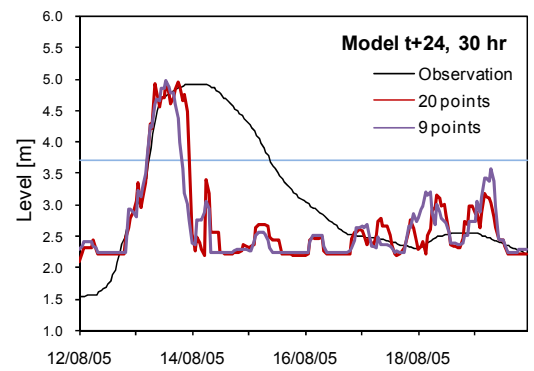

Figure 8. Hydrographs of model $\mathrm{t}+24$ using only radar image with 9 and 20 points.

the actual. Therefore, this study focus on investigation the combination input between water level and raw $\mathrm{dBZ}$ value from radar image, it might improve the model performance i.e. to increase the lead time and the falling limb of hydrograph.

For model development, when the inputs were chosen, network with 10 hidden nodes were
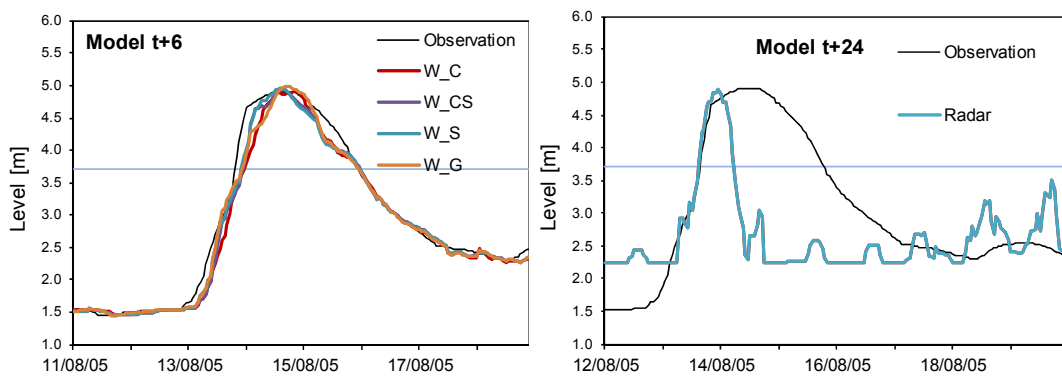

Figure 9. Hydrographs of model $t+6$ using only water level $(\mathrm{W})$ and $t+24$ using only radar image as the input. trained with Bayesian Regularisation. The total 63 variables were compiled including 36 input variables of river levels (P1, P67 and P75) at time t, t-3, t-6 continuing at 3 hour intervals to t-24 hours and moving averages over the previous 6,12 and 24 hours, and 27 input variables of radar images ( 9 sample points) the 
Chaipimonplin et al., Improving neural network for flood forecasting using radar data...

accumulated $\mathrm{dBZ}$ value of the radar image at each sample point at time t, t-6 and t-12 hours. The input data used in the model include three water level gauging stations (P1, P75 and P67) and radar images, all of which were available at an hourly time scale. The location of sample points in radar images are shown in Figure 5.

\section{RESULTS}

\subsection{Water and radar (WR)}

Figure 10 provides hydrographs of observed and predicted water level for lead times of 12, 18 and 24 hours with four input determination techniques; S, G, CS and C. It is clear that combination between water level stations and radar image as the input improved the overall performance, especially in the falling limb of the hydrograph at $\mathrm{t}+24$, also the lead time increased from $6 \mathrm{hr}$ to 12 and $18 \mathrm{hr}$ with approximately $2 \mathrm{hr}$ delay. In contrast, at the lead time $\mathrm{t}+24 \mathrm{hr}$, the model performance is decreased as model predicted more than $5 \mathrm{hr}$ delay from the actual event.

All four models predicted very similar at the rising limb at the lead time $\mathrm{t}+12$ as only $1-2 \mathrm{hr}$ delays but at the peak only model $\mathrm{G}$ predicted less than $1 \mathrm{~cm}$ over the actual peak. At $\mathrm{t}+18 \mathrm{hr}$, all model predicted delay approximately 3-4 hr and overestimated at the peak but only model $\mathrm{S}$ was underestimated. Model S was the only model that selected more radar images (Table 1). It resulted the lowest falling limb of the hydrograph at $\mathrm{t}+12$ and 18 . In contrast, other three models selected only one or two input variables from radar images which was point Z22, that was the nearest the Ping river. As expected that model CS was the worst model for predict 18 hour lead time particularly at the rising limb. It is because of selecting input variables only P75t and P67t, therefore this model would be insufficient for neural network model. In addition, predicted water level for lead time of $24 \mathrm{hr}$, does not

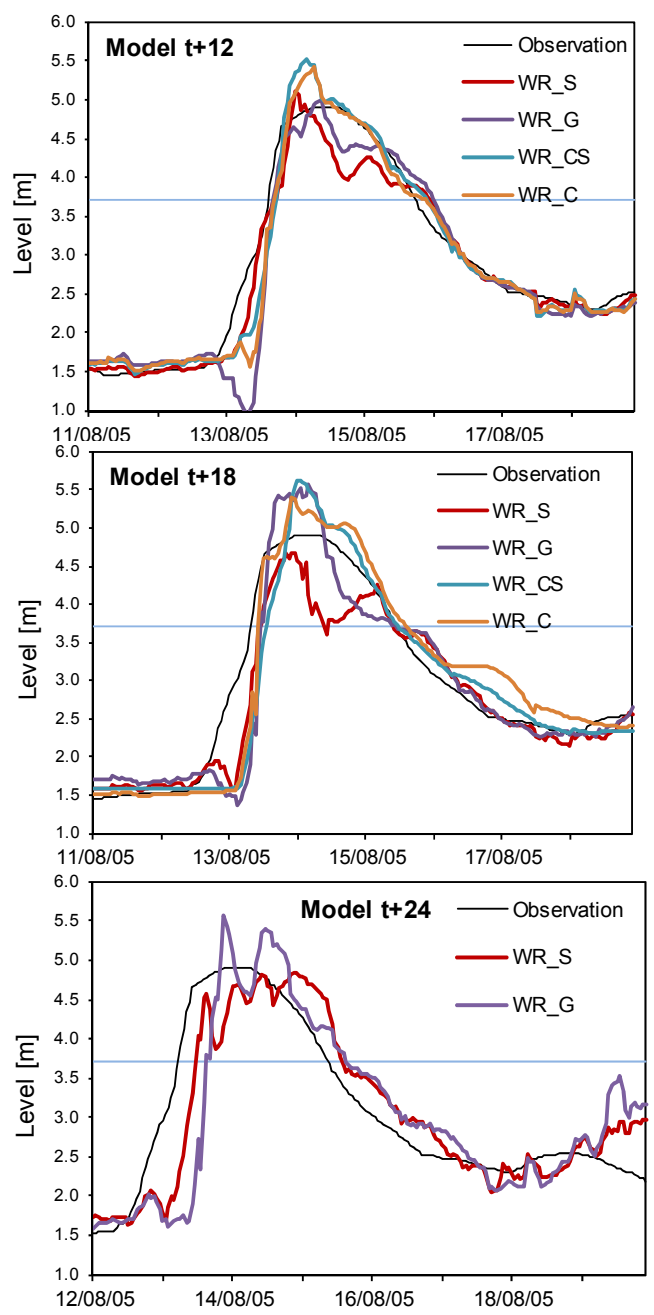

Figure 10. Hydrographs of model at $\mathrm{t}+12,18$ and $24 \mathrm{hr}$ using water level and radar image (WR) as the inputs. have any variable with correlation $>0.9$, therefore models $\mathrm{C}$ and CS were not included in this study. Table 2 provides evaluation measures for the ANNs models developed for the three lead times using the different input determination techniques. The results show that model CS was the best model at $\mathrm{t}+12$ as $\mathrm{CE}$ value was high and only $1.711 \mathrm{~cm}$ error also model $\mathrm{C}$ was the best at $\mathrm{t}+18$ with $1.744 \mathrm{~cm}$ error.

Table 1. Input remaining for each input determination techniques.

\begin{tabular}{|c|c|c|c|c|c|c|c|c|c|c|c|c|c|c|c|c|c|c|c|c|c|}
\hline \multirow{2}{*}{ Input } & \multicolumn{4}{|c|}{$\mathrm{T}+12$} & \multicolumn{4}{|c|}{$T+18$} & \multicolumn{2}{|c|}{$T+24$} & \multirow{2}{*}{ Input } & \multicolumn{4}{|c|}{$T+12$} & \multicolumn{4}{|c|}{$T+18$} & \multicolumn{2}{|c|}{$T+24$} \\
\hline & $\mathbf{S}$ & G & CS & C & $\mathbf{S}$ & G & CS & $\mathrm{C}$ & $\mathbf{S}$ & G & & $\mathbf{S}$ & G & CS & C & $\mathbf{S}$ & G & CS & C & $\mathbf{S}$ & G \\
\hline P1t-24 & $\mathrm{X}$ & & & & & & & & & $\mathrm{X}$ & Z21 & $\mathrm{X}$ & & & & & & & & & \\
\hline P1t-21 & & & & & & & & & & & $\mathrm{Z} 22$ & $\mathrm{X}$ & & & & $\mathrm{X}$ & $\mathrm{X}$ & & & $\mathrm{X}$ & X \\
\hline P1t-18 & $\mathrm{X}$ & & & & & $X$ & & & & & Z23 & $\mathrm{X}$ & $\mathrm{X}$ & & & & & & & $\mathrm{X}$ & \\
\hline P1t-15 & & $\mathrm{X}$ & & & & & & & & & $\mathrm{Z} 31$ & $\mathrm{X}$ & & & & $\mathrm{X}$ & & & & $\mathrm{X}$ & \\
\hline P1t-12 & & $\mathrm{X}$ & & & $X$ & & & & & & Z32 & $\mathrm{X}$ & & & & $\mathrm{X}$ & & & & $\mathrm{X}$ & \\
\hline P1t-9 & & & & & & & & & & & Z33 & $\mathrm{X}$ & & & & $\mathrm{X}$ & & & & $\mathrm{X}$ & \\
\hline P1t-6 & & & & $\mathrm{X}$ & & $X$ & & & & $X$ & Z41 & $\mathrm{X}$ & & & & $\mathrm{X}$ & & & & $\mathrm{X}$ & \\
\hline P1t-3 & $\mathrm{X}$ & & & $\mathrm{X}$ & $X$ & & & & $X$ & & Z42 & & & & & & & & & $\mathrm{X}$ & \\
\hline P1t & $\mathrm{X}$ & & $\mathrm{X}$ & $\mathrm{X}$ & $\mathrm{X}$ & $X$ & & & $X$ & & Z43 & $\mathrm{X}$ & & & & $\mathrm{X}$ & & & & $\mathrm{X}$ & \\
\hline MVP1-6 & & $\mathrm{X}$ & & $\mathrm{X}$ & & $X$ & & & & $\mathrm{X}$ & $6 Z 21$ & & & & & $X$ & & & & $\mathrm{X}$ & \\
\hline MVP1-12 & & $\mathrm{X}$ & & $\mathrm{X}$ & & & & & & $\mathrm{X}$ & $6 Z 22$ & $\mathrm{X}$ & & & & $X$ & & & & $\mathrm{X}$ & \\
\hline MVP1-24 & & & & & & & & & & & $6 Z 23$ & & & & & $X$ & & & & $\mathrm{X}$ & \\
\hline P75t-24 & & & & & $\mathrm{X}$ & & & & & & $6 Z 31$ & $\mathrm{X}$ & & & & $\mathrm{X}$ & & & & & \\
\hline P75t-21 & $X$ & & & & & & & & & & $6 Z 32$ & & & & & $\mathrm{X}$ & & & & $\mathrm{X}$ & \\
\hline P75t-18 & & $\mathrm{X}$ & & & $\mathrm{X}$ & & & & & & $6 Z 33$ & & & & & $\mathrm{X}$ & & & & $\mathrm{X}$ & \\
\hline
\end{tabular}


Chaipimonplin et al., Improving neural network for flood forecasting using radar data...

\begin{tabular}{|c|c|c|c|c|c|c|c|c|c|c|c|c|c|c|c|c|c|c|c|c|c|}
\hline P75t-15 & $\mathrm{X}$ & & & & & & & & & & $6 Z 41$ & & & & & & & & & & \\
\hline P75t-12 & & & & & & $\mathrm{X}$ & & & & & $6 Z 42$ & & & & & & & & & & \\
\hline P75t-9 & $\mathrm{X}$ & & $\mathrm{X}$ & $\mathrm{X}$ & & & & & & $\mathrm{X}$ & $6 Z 43$ & & & & & $\mathrm{X}$ & & & & $\mathrm{X}$ & \\
\hline P75t-6 & & & & $\mathrm{X}$ & & $\mathrm{X}$ & & & & $\mathrm{X}$ & $12 \mathrm{Z} 21$ & $\mathrm{X}$ & & & & $\mathrm{X}$ & & & & $\mathrm{X}$ & \\
\hline P75t-3 & & $\mathrm{X}$ & & $\mathrm{X}$ & & $\mathrm{X}$ & & & & $\mathrm{X}$ & $12 Z 22$ & & $\mathrm{X}$ & $\mathrm{X}$ & $\mathrm{X}$ & & $\mathrm{X}$ & & $\mathrm{X}$ & & $\mathrm{X}$ \\
\hline $\mathrm{P} 75 \mathrm{t}$ & $\mathrm{X}$ & $\mathrm{X}$ & $\mathrm{X}$ & $\mathrm{X}$ & $\mathrm{X}$ & $\mathrm{X}$ & $\mathrm{X}$ & $\mathrm{X}$ & $\mathrm{X}$ & $\mathrm{X}$ & $12 \mathrm{Z} 23$ & $\mathrm{X}$ & & & & $\mathrm{X}$ & & & & $\mathrm{X}$ & \\
\hline MVP75-6 & & $\mathrm{X}$ & & $\mathrm{X}$ & $\mathrm{X}$ & & & & $\mathrm{X}$ & & $12 Z 31$ & $\mathrm{X}$ & & & & $\mathrm{X}$ & & & & & \\
\hline MVP75-12 & & & & $\mathrm{X}$ & $\mathrm{X}$ & $\mathrm{X}$ & & & & $\mathrm{X}$ & $12 \mathrm{Z} 32$ & $\mathrm{X}$ & & & & $\mathrm{X}$ & & & & $\mathrm{X}$ & \\
\hline MVP75-24 & & & & & & $\mathrm{X}$ & & & & & $12 \mathrm{Z33}$ & & & & & $\mathrm{X}$ & & & & $\mathrm{X}$ & \\
\hline P67t-24 & & & & & $\mathrm{X}$ & & & & $\mathrm{X}$ & & $12 Z 41$ & & & & & & & & & & \\
\hline P67t-21 & & & & & & & & & & & $12 Z 42$ & $\mathrm{X}$ & & & & $\mathrm{X}$ & & & & $\mathrm{X}$ & \\
\hline P67t-18 & & $\mathrm{X}$ & & & & & & & & $\mathrm{X}$ & $12 Z 43$ & $\mathrm{X}$ & & & & $\mathrm{X}$ & & & & $\mathrm{X}$ & \\
\hline P67t-15 & $\mathrm{X}$ & & & & $\mathrm{X}$ & $\mathrm{X}$ & & & & & Total (63) & 27 & 14 & 7 & 17 & 32 & 14 & 2 & 3 & 28 & 15 \\
\hline P67t-12 & & & & & & & & & $\mathrm{X}$ & & & & & & & & & & & & \\
\hline P67t-9 & & & & $\mathrm{X}$ & & & & & & & & & & & (5) & 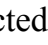 & inp & $v$ & 016 & & \\
\hline
\end{tabular}

\begin{tabular}{|c|c|c|c|c|c|c|c|c|c|c|}
\hline P67t-6 & & & & X & & & & & & \\
\hline P67t-3 & & $\mathrm{X}$ & & $\mathrm{X}$ & & $\mathrm{X}$ & & & & $\mathrm{X}$ \\
\hline $\mathrm{P} 67 \mathrm{t}$ & $\mathrm{X}$ & $\mathrm{X}$ & $\mathrm{X}$ & $X$ & $\mathrm{X}$ & & $\mathrm{X}$ & $\mathrm{X}$ & $\mathrm{X}$ & $\mathrm{X}$ \\
\hline MVP67-6 & $\mathrm{X}$ & & X & $\mathrm{X}$ & $\mathrm{X}$ & & & & $\mathrm{X}$ & $\mathrm{X}$ \\
\hline MVP67-12 & & & $\mathrm{X}$ & X & & & & & & \\
\hline MVP67-24 & & $\mathrm{X}$ & & & & & & & & \\
\hline
\end{tabular}

Table 2. Statistics for all models developed using river level and radar images as the input.

\begin{tabular}{|l|c|c|c|c|c|c|c|c|c|c|}
\hline \multirow{2}{*}{ Lead times } & \multicolumn{4}{|c|}{$\mathrm{T}+12$} & \multicolumn{4}{c|}{$\mathrm{T}+18$} & \multicolumn{2}{c|}{$\mathrm{T}+24$} \\
\cline { 2 - 12 } & $\mathrm{S}$ & $\mathrm{G}$ & $\mathrm{CS}$ & $\mathrm{C}$ & $\mathrm{S}$ & $\mathrm{G}$ & $\mathrm{CS}$ & $\mathrm{C}$ & $\mathrm{S}$ & $\mathrm{G}$ \\
\hline No. of input & 27 & 14 & 7 & 17 & 32 & 14 & 2 & 3 & 28 & 15 \\
\hline PDIFF & -0.213 & -0.085 & -0.616 & -0.533 & 0.226 & -0.673 & -0.716 & -0.494 & 0.055 & -0.671 \\
\hline MAE & 0.097 & 0.1393 & 0.100 & 0.103 & 0.194 & 0.214 & 0.177 & 0.174 & 0.046 & 0.053 \\
\hline RMSE & 0.172 & 0.259 & 0.171 & 0.186 & 0.292 & 0.333 & 0.299 & 0.287 & 0.149 & 0.198 \\
\hline CE & 0.963 & 0.918 & 0.964 & 0.957 & 0.895 & 0.863 & 0.890 & 0.898 & 0.973 & 0.953 \\
\hline
\end{tabular}

\subsection{Radar (R)}

This section is the comparison of input determination techniques; Stepwise regression (S) and Genetic algorithms (G) and use all radar input variables (R).It is obvious that selecting most appropriate input variable improves the model performance (Figure 11). Model S and G predicted earlier than model $\mathrm{R}$ and the actual event but both models $\mathrm{S}$ and $\mathrm{G}$ were overestimated at the peak. Moreover, model S predicted $1 \mathrm{hr}$ earlier than model $\mathrm{G}$, also predicted better at the peak even though, model $\mathrm{S}$ selected only 5 input variables (Table 1). It could be said that selecting only sample points of $\mathrm{dBZ}$ value along the river would be sufficient information.

\section{DISCUSSION AND CONCLUSIONS}

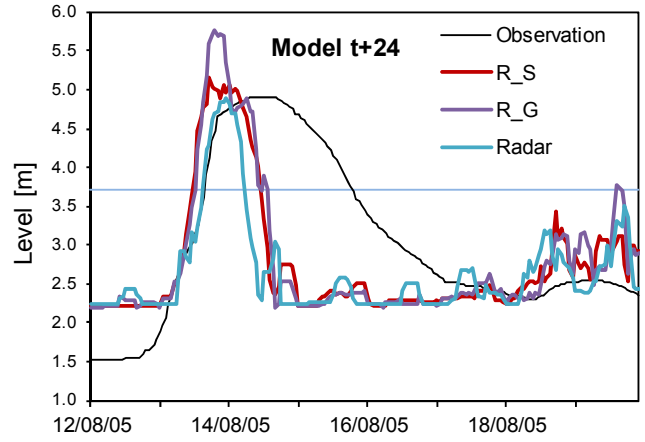

Figure 11. Hydrographs of model predictions at $\mathrm{t}+24 \mathrm{hr}$ using only radar image (R) as the input.

The results clearly show that it is possible to increase the lead time of the forecast using only raw dBZ value by a considerable amount, i.e. $24 \mathrm{hr}$ lead time. Unfortunately, the model cannot predict the full hydrograph, especially the falling limb when compared with models using only water level. However, using both raw radar and three water stage stations as input variables improved the falling limb but the lead time of prediction dropped back to 12 hours with a $8 \mathrm{~cm}$ error in peak prediction. Using only raw dBZ radar image as the input is possible to predict the rising limb of the hydrograph and the peak very accurately at considerably longer lead times, i.e. 24 hours, compared to the ANNs models developed using only river levels. However, combination input variables between water level and radar images improved the overall performance especially the falling limb but it decreases the lead time from 24 to 12 hours.

The preferred input variables for this study seem to be P1t, P75t, P67t, Z22 and 12Z22. However, dBZ value has less correlation as only one variable (12Z22) was selected with Correlation method. However, storm movement patterns and wet/dry conditions in the catchment will influence the ability of the neural networks 
Chaipimonplin et al., Improving neural network for flood forecasting using radar data...

to accurately predict the flood using radar data. The results of this study can only be considered to be indicative with such a small number of storm events for training and testing, and missing radar data for the first two storms in 2006, the model could not be calibrated separately for different rainfall patterns with enough confidence to draw conclusions. However, the potential of using raw dBZ value in this way was clearly demonstrated. It is recommended for the future study is adding more sample points alone the Ping River (around Z22) and testing with other storm event. Fortunately, acquiring all water level data and radar images between academic institutes and government departments are free of charge in Thailand.

\section{ACKNOWLEDGMENTS}

We would like to give our thanks to Chiang Mai University, Thailand for financial support for this research. Also thanks to the Hydrology and Water Management Center for the Upper Northern Region for the water level data, the Bureau of Royal Rainmaking and Agricultural Aviation in Thailand for the radar images and to Mr. Chanti Deiyothin who developed the program for extracting the radar from the images.

\section{REFERENCES}

Abrahart, R.J., See, L.M., Dawson, C.W., Shamseldin, A.Y. and Wilby, R.L. (2010). Nearly Two Decades of Neural Network Hydrological Modeling. In: Sivakumar, B. and Berndtsson, R. (Eds.) Advances in DataBased Approaches for Hydrologic Modeling and Forecasting. World Scientific.

ASCE (2000). Artificial neural networks in hydrology. I: Preliminary concepts. Journal of Hydrologic Engineering, 5, 115-123.

Anctil, F. (2007). Tools for the assessment of hydrological ensemble forecasts. In: Proceedings of the international Workshop on Advances in Hydroinformatics 2007, Coulibaly, P (Eds.), 4-7 June, Niagara Falls, Canada.

Boochabun, K., Tych, W., Chappell, N.A., Carling, P.A., Lorsirirat, K. and Pa-Obsaeng, S. (2004). Statistical modelling of rainfall and river flow in Thailand. Journal of the Geological Society of India, 64, 503-515.

Chaipimonplin, T. (2010). An Exploration of Neural Network Modelling Options for the Upper River Ping, $\mathrm{PhD}$ thesis, School of Geography, University of Leeds.

Chaipimonplin, T., See, L.M. and Kneale, P.E. (2010). Using radar data to extend the lead time of neural network forecasting on the River Ping. Disaster Advances, 3(3), 35-43.

Chaipimonplin, T., See, L.M. and Kneale, P.E. (2008). Neural network prediction of flooding in Chiang Mai, Thailand: comparison of input determination techniques. EGU, Vienna, Austria, 13-18 April 2008.

Chumchean, S. (2007). Investigation of climatological Z-R relationship for Pasicharoen radar, The Second National Convention on Water Resources Engineering (published in Thai). Kasetsart University, Bangkok, Thailand: The Engineering Institute of Thailand under H.M. The King's Patronage.

Cole, S.J. and Moore, R.J. (2008). Hydrological modeling using raingauge and radar based estimators of areal rainfall. Journal of Hydrology, 358, 159-181.

Department of Water Resources (2007). Ping catchment [Online], [Accessed 16 November 2008], available at http://mekhala.dwr.go.th/mekhal/Basin North.asp.

Hydrology and Water Management Centre for Upper Northern Region (2007a). Upper Northern Region Flood Warning Brochures [Online], [Accessed 16 November 2007], Available at http://www.hydro-1.net.

Hydrology and Water Management Centre for Upper Northern Region (2007b). Ping Report [Online], [Accessed 16 November 2007], available at http://www.hydro-1.net/DATASHOW/dspic/ping-report.html.

Maier, H.R., Jain, A., Dandy, G.C. and Sudheer, K.P. (2010). Methods used for the development of neural networks for the prediction of water resource variables in river systems: Current status and future directions. Environmental Modeling \& Software, 25, 891-909.

Mapiam, P. and Sriwongsitanon, N. (2009). Estimation of the URBS model parameters for flood estimation of ungauged catchments in the upper Ping river basin, Thailand. Sciences Asia, 35, 49-56.

Northern Meteorological Centre (2007). Climatology data for the period 30 years (1971-2000). Thai Meteorological Department, Chiang Mai.

Rachaneewan, T. (2006). Radar rainfall estimates, Bureau of Royal Rainmaking and Agricultural Aviation, Ministry of Agriculture and Cooperatives, Bangkok.

Taesombat, W. and Sriwongsitanon, N. (2010). Flood investigation in the Upper Ping River Basin using mathematical models. Kasetsart Journal Natural Science, 44, 152-166.

Wardah, T., Bakar, S.H.A., Bardossy, A. and Maznorizan, M. (2008). Use of geostationary meteorological satellite images in convective rain estimation for flash-flood forecasting. Journal of Hydrology, 356, 283298.

Witten, I.H. and Frank, E. (2005). Data Mining Practical Machine Learning Tools and Techniques, Morgan raufmann Publishers. 